Session 1566

\title{
The Creative Design Workshop: Learning and Discovery through Reverse Engineering
}

\author{
Madara Ogot \\ Department of Mechanical and Aerospace Engineering \\ Rutgers, The State University of New Jersey
}

\begin{abstract}
The Creative Design Workshop is based on an existing learning model that currently operates on virtually all university campuses - the college newspaper. What better way to train future journalists than have them work in a real newspaper environment, honing their interview and writing skills, while at the same time providing an invaluable service to the university community. Similarly, the Creative Design Workshop initiated in Fall 2001 at Rutgers University, operates like an 'Engineering Company'. Its mission is the development of multimedia materials describing how mechanical engineering systems work and the rationale behind their design (training). The materials will be developed at the level of high school seniors and university freshmen with the aim of attracting more of these students into engineering careers (service to the community).
\end{abstract}

\subsection{Introduction}

In a two-year survey of some 1000 employers in industry and government carried out in the early nineties by the National Society of Professional Engineers (NSPE), $80 \%$ of the respondents placed a high value on teamwork, with only $25 \%$ expressing the opinion that engineering schools adequately prepared students in this area. In addition, when asked what areas in the curriculum need more merit in a revised curriculum, $60 \%$ felt that the students needed to improve their communications skills, while $45 \%$ felt that they should get more practical experience ${ }^{1}$. Further, a recent NSF report stated that, 'Too many graduates go out into the workforce ill-prepared to solve real problems in a cooperative way, lacking the skills and motivation to continue learning. ${ }^{2}$.

In response to this and other similar studies, engineering schools over the past decade have made significant advances and innovations in the way engineering is taught at the undergraduate level. 
Specifically, in Mechanical Engineering, approaches have varied from more hands on learning experiences - for example, product dissection courses at Stanford ${ }^{3}$ and the $\mathrm{MEEP}^{\dagger}$ coalition ${ }^{4}$, and industry-sponsored capstone senior design courses - to the adoption of different teaching styles in the classroom ${ }^{2,5}$.

Despite these efforts several problems still remain. These include:

1. A majority of mechanical engineering students graduate with a poor feel for how common mechanical devices work and the rationale behind their design ${ }^{4}$.

2. A majority of engineering students have little exposure with the use of multimedia software and hardware ${ }^{6}$.

3. Poor oral and written communication skills amongstst ME graduates despite their introduction into the curriculum ${ }^{1,2}$.

4. A need to attract more students, especially from diverse populations, into engineering ${ }^{7}$.

The Creative Design Workshop $(C D W)$ described in this paper, addresses each of the problems enumerated above.

\subsection{Creative Design Workshop}

The CDW is based on an existing learning model that currently operates on virtually all university campuses - the college newspaper. What better way to train future journalists than have them work in a real newspaper environment, honing their interview and writing skills, while at the same time providing an invaluable service to the university community.

Similarly, the $C D W$ operates like an 'Engineering Company' whose mission is to develop multimedia presentation materials describing how mechanical engineering systems work and the rationale behind their design (training). The materials are developed at the level of high school seniors and university freshmen with the aim of attracting more of these students into engineering careers (service to the community).

Unlike the college newspaper model, however, the CDW has more structure and is integrated into the department curriculum. Students in the CDW are primarily sophomores, juniors and seniors enrolled in the Mechanical Engineering program, plus a few students from other engineering departments. They form 'Research and Development' teams charged with the reverse engineering of several devices/systems. Drawing upon their current knowledge and through their guided research efforts, the R\&D teams then develop multimedia presentation materials in CD-ROM format on how each device/system works. The materials include a discussion of some of the salient design issues and presentation notes. The mixed composition of the R\&D teams encourage peer-teaching, cooperative learning and the development of leadership qualities in the senior members. The CDW achieves its goals through several Specific Aims discussed next.

\footnotetext{
† The MEEP Coalition consists of the Pennsylvania State University, the University of Washington, and the University of Puerto Rico-Mayaguez. 


\subsection{Specific Aim \#1: Introduce an Inquiry-based, Cooperative Learning Environment}

Engineering educators have long noted that lectures though efficient at delivering large amounts of analytical information, encourage passivity in students who come to expect the instructor to provide all the required knowledge ${ }^{4}$. Johnson et al. ${ }^{8}$ noted that: 'lecturing at best tends to focus on the lower-level of cognition and learning. When the material is complex, detailed or abstract; when students need to analyze, synthesize, or integrate the knowledge being studied; or when long term retention is required, lecturing is not such a good idea.' Other researchers have found that lectures tend to alienate active and reflective learners - the active learners do not do anything, while the reflective learners do not have time to reflect. As a result, both are lulled into inattention by enforced passivity ${ }^{9,10}$. Also, lectures do not adequately take into account varied student learning styles ${ }^{11,12}$. Many engineers are actually 'active, visual learners', much better served by active, visual and tactile teaching methods ${ }^{13-16}$.

Further, one of the imperatives identified by the Advisory Committee to the National Science Foundation Directorate for Education and Human Resources, was that '..... all students learn [Science, Mathematics, Engineering and Technology] subjects by direct experience with the methods and processes of inquiry. ${ }^{2}$ The inquiry-based method of learning by students in the $\mathrm{CDW}$ addresses these concerns. The approach, which incorporates both active and cooperative learning models, arouses the students' natural curiosity, nurtures their sense of wonder and encourages wide-eyed exploration that can last a lifetime.

A schematic of the CDW structure is illustrated in Figure 1. Modules I-IV refer to the fourcourse sequence which embodies the CDW's activities. Each semester, CDW students enroll in the course that corresponds to their length of service. All students can only join the CDW in the Fall semester of each year. Students participating for the first time (junior members) enroll in Module I: Engineering Communication via emerging technologies in the Fall. The 1.5 credits, for credit course, concentrates on teaching the students how to use several multi-media software tools. In the spring semester, junior members register for the 1.5 credit, for credit, Module II: Reverse Engineering - I. Returning students (senior members) register for 1.5 credit (non-credit) Module III: Instructional Practicum in the fall and Module IV: Reverse Engineering II (1.5 Credits, non-credit) in the spring.

Unlike traditional courses, all students meet at the same time although enrolled in different courses. This arrangement further allows the CDW to be managed by a single faculty member. The courses follow a seminar format, encouraging direct interaction and lively discussions between all participants. 


\begin{tabular}{|c|c|c|}
\hline & Fall Semester & Spring Semester \\
\hline $\begin{array}{l}\text { R\&D Team } \\
\text { Members }\end{array}$ & $\begin{array}{l}\text { Junior Members in } \\
\text { Module I } \\
\text { Senior Members in } \\
\text { Module III }\end{array}$ & $\begin{array}{l}\text { Junior Members in } \\
\text { Module II } \\
\text { Senior Members in } \\
\text { Module IV }\end{array}$ \\
\hline Focus & Training & $\begin{array}{c}\text { Problem-based Learning } \\
\text { and Discovery }\end{array}$ \\
\hline $\begin{array}{l}\text { Products/ } \\
\text { Service }\end{array}$ & $\begin{array}{l}\text { High School } \\
\text { Lectures }\end{array}$ & \begin{tabular}{|c|} 
Multimedia Presentations \\
High School \\
Lectures
\end{tabular} \\
\hline \multicolumn{3}{|c|}{$\begin{array}{l}\text { Module I: Engineering Communication via emerging technolgies } \\
\text { Module II: Reverse Engineering - I } \\
\text { Module III: Instructional Practicum } \\
\text { Module IV: Reverse Engineering - II }\end{array}$} \\
\hline
\end{tabular}

Figure 1. Structure of the Creative Design Workshop

\subsection{Specific Aim \#2: Give Mechanical Engineering Students a 'Good Feel' for How Mechanical Engineering Systems Work and the Rationale Behind Their Design}

Each spring semester, all students in the CDW participate in the reverse engineering and development of corresponding multimedia materials for mechanical systems. Physical experiences with real-life examples can be instrumental in reinforcing theory, enhancing retention and serve as a mental 'bookmark' for future recall ${ }^{4}$. Reverse engineering or product dissection courses have been introduced within engineering programs at other Universities, for example, Stanford University ${ }^{3}$ and the MEEP coalition ${ }^{4}$. These courses are modular in nature, with students dissecting several devices per semester. For each device, the dissection steps are well laid out, with the associated theoretical foundation discussed in lecture. Such an approach allows the courses to be introduced fairly early in the students' academic career.

The CDW model, however, is more open-ended. It does not lay out the dissection steps nor provide detailed background materials on the devices or systems under investigation. Based on their research, the R\&D teams themselves determine the associated theoretical foundation, the rationale behind the design and the best dissection steps necessary to determine how the devices work. This approach allows the students to directly apply their classroom knowledge and the results of their own research to solving the problem. At the end of the academic year, each R\&D team will have developed, on CD-ROM, a multimedia presentation with accompanying presentation notes for a mechanical device/system. This approach to reverse engineering is more 'research-oriented' than the traditional 'menu-driven' approach and therefore exposes students to the 'research process'. 


\subsection{Specific Aim \#3: Exposing students to Emerging Multi-Media Technologies.}

A typical engineering curriculum does not offer students the opportunity to learn and use emerging multi-media technologies in the areas of computer graphics, animation and video. Yet, these technologies are playing an increasing role in industry, especially in the areas of simulation, computer-aided design and engineering communication. Using visual content to communicate complex engineering processes and calculations, for example embedding video and animations into PowerPoint ${ }^{\circledR}$ presentations, is rapidly becoming the norm at professional meetings as the tools to do so become increasingly available. In addition, as the use of these tools becomes more common, it is important for students to understand the terminology associated with their use. For example, most of our students at the onset did not know the difference between a .jpeg or a .gif graphical file, or an .mpeg or a .ram video file. Others could not associate .jpeg or .mpeg with either file type.

The CDW, therefore, gives students formal instruction in the use of some of the common multimedia tools and have them apply that knowledge in the creation of their multi-media presentations. Although the actual software taught will change with market trends, students were exposed to Adobe Photoshop $^{\circledR}$, Corel Draw ${ }^{\circledR}$, Macromedia Flash ${ }^{\circledR}$ and iMovie $^{\circledR}$ during the 2001/2002 academic year.

\subsection{Specific Aim \#4: Improvement of Student Communication Skills}

Students receive formal training on making oral presentations and writing technical reports, with particular emphasis on the use of multimedia technologies. In the spring semester with students registered for Reverse Engineering I/II (refer to Figure 1), the R\&D teams hold joint weekly meetings where team members present progress of the past week for review and plans for next week. All CDW members provide assistance and make suggestions where necessary. The aim is for students to become accustomed to making frequent presentations in front of an audience and writing concise progress reports.

Formal instruction on teaching methods and learning styles as well as training on currently available instructional technologies is given to senior members in Module III: Instructional Practicum. Using this knowledge, senior members then teach junior members (under supervision of the faculty member) on multi-media technologies in Module I: Engineering Communication via Emerging Technologies. It is hoped that by having students teach a portion of a course, their interest in teaching may be aroused leading to eventual careers as faculty members. This module of the CDW strives to fill a void that is present in nearly all engineering curriculums: exposing undergraduates to a teaching experience thereby allowing them to explore the possibility of careers in teaching. This module also develops an important skill for those students who go into industry upon graduation: the ability to make clear oral presentations and to effectively train others. These skills will lay the foundation for CDW graduates to become the industry leaders of tomorrow. 


\subsection{Specific Aim \#5: Encouraging More High School Seniors to Consider Careers in Engineering}

As previously mentioned, the 'product' of the Creative Design Workshop, are multi-media presentations on CD-ROM of common mechanical devices/systems work. On completion of each project, student R\&D teams visit local high schools to make their presentations and hopefully arouse the interest of high school students to engineering. We have been working with two local high schools in New Brunswick and Franklin Township (NJ), both of which have high minority populations.

In the near future, we shall have all developed materials available for download from the program website to allow high school teachers to incorporate the materials into their classrooms.

\subsection{Concluding Remarks}

On completion of the four course sequence, the CDW students will have had formal instruction on engineering communication via emerging technologies, teamwork, teaching methods, and learning styles; participated in the detailed reverse engineering of two devices/systems with the development of accompanying multimedia presentations materials; conducted a seminar to their peers; and presented a formal lecture a local high school class. In summary The Creative Design Workshop will have:

1. Enabled students to tie-together through hands-on, problem-based learning the knowledge they have acquired as they reverse engineer different mechanical engineering systems

2. Significantly improved the students oral and written communication skills complemented with emerging multimedia technologies

3. Nurtured the students' abilities to work in teams

4. Exposed students to the research process, and

5. Increased high school seniors' interest in engineering.

The CDW has just completed its first year, and it is therefore too early to quantitatively tell if all the goals have been met. Future publications will include both quantitative and qualitative evaluations of the program and assess the impact it has made.

\section{Acknowledgment}

The author would like to acknowledge the National Science Foundation for support of this project through a grant under the CCLI program.

\section{Bibliography}

1. Dahir, M., 'Educating Engineers for the Real World', Technology Review, vol. 96, August/September, 1993, pp. 14-16

2. National Science Foundation, 'SHAPING THE FUTURE: New Expectations for Undergraduate Education in Science, Mathematics, Engineering, and Technology’ Arlington, VA, (NSF 96-139), 1996.

3. Shepard, S. D., 'Mechanical Dissection: An Experience in How Things Work' Proceedings of the Engineering Education Conference on Curriculum Innovation and Integration, 1992. 
4. Lamancusa, J, M., Torres, V. Kumar and J. Jorgensen, 'Learning Engineering by Product Dissection' Proceedings of ASEE Annual Conference, 1996, pp. 1-12

5. Lamancusa, J. M., Jorgensen, J.E, Zayas-Castro, J.L. and Ratner, J., 'The Learning factory - A New Approach to integrating design and manufacturing into the engineering curricula' Proceedings of ASEE Annual Conference, 1995, pp. 2262-2269

6. Senior Exit Survey, Mechanical and Aerospace Engineering Department, Rutgers University, 2001.

7. National Science Foundation. 'Women, Minorities and Persons with Disabilities in Science and Engineering: 1998', Arlington, VA, (NSF 99-338), 1999.

8. Johnson. D.W., R. T. Johnson and K.A. Smith, Active Learning: Cooperation in the Classroom, Interaction, Edina MN, 1991.

9. Kolb, D., Experiential Learning: Experience as the Source of Learning and Development. Prentice-Hall, Englewood Cliffs, 1984.

10. Felder, R.M., 'Reaching the Second Tier-Learning and Teaching Styles in College Science Education', Journal of College Science Teaching, vol. 23, no. 5, March/April, 1993, pp. 286-290.

11. Mestre, J.P. "Cognitive Aspects of Learning and Teaching Science' Pre-College Teacher Enhancements in Science and Mathematics: Status, Issues and Problems, S.J. Fitzsimmons and L.C. Kerpelman (Eds.), National Science Foundation, Washington, DC, 1991.

12. Koen, B.V., 'Toward a Strategy for Teaching Engineering Design', Engineering Education, vol. 83, no.3, 1994, pp. 193-202.

13. Felder, R.M. and L.K. Silverman, "Learning and Teaching Styles in Engineering Education” Engineering Education, vol. 78, no. 7, April 1988, pp. 674-681.

14. Svinicki, M.D. and Dixon, N.M. 'The Kolb Model Modified for Classroom Activities', College Teaching, vol. 35, no. 4, 1991, pp. 141-146.

15. Myers, C. and T. Jones, Promoting Active Learning: Strategies for the College Classroom, Jossey-Bass, San Francisco, 1993.

16. Wankat, P.C. and Oreovicz, F.S., 'A Different Way of Teaching’ ASEE Prism, January 1994, pp. 15-19.

\section{Biography}

MADARA OGOT is an associate professor in Mechanical Engineering at Rutgers University where he serves as Undergraduate Director. His current research interests include design under uncertainty and recovery of energy from ocean waves. He received his BSE from Princeton in 1987, and his MS and Ph.D. from the Pennsylvania State University in 1989 and 1991, respectively. 